\title{
ДИНАМІЧНЕ АНАЛІЗУВАННЯ МЕХАНІЗМУ ДОВБАЛЬНОГО ВЕРСТАТА
}

\author{
В'ячеслав Пасіка ${ }^{1}$, д. т. н., Петро Коруняк ${ }^{2}$,. т. н., \\ Володимир Зохнюк ${ }^{1}$, Дмитро Роман ${ }^{1}$ \\ ${ }^{1}$ Національний університет «Львівська політехніка», \\ вул. С. Бандери, 12, м. Львів, Украӥна, \\ e-mail:paswr@meta.ua,volodymyr.zokhniuk.mb.2019@lpnu.ua,dmytro.roman.mb.2019@lpnu.ua \\ ${ }^{2}$ Львівський національний аграрний університет, \\ вул. Володимира Великого, 1, м. Дубляни, Львівський р-н, Львівська обл., Украӥна, \\ e-mail:petrokoruniak@gmail.com
}

https://doi.org/10.31734/agroengineering2021.25.042

Пасіка В., Коруняк П., Зохнюк В., Роман Д. Динамічне аналізування механізму довбального верстата

Кінематичні характеристики ланок і окремих точок механізму визначені методом замкнутих геометричних контурів та методом проєктування планів. Сили взаємодії між ланками механізму визначені методом кінетостатики, а зрівноважувальний момент - розглядом динамічної рівноваги корби. Також зрівноважувальний момент визначений методом балансу потужностей. Похибка не перевищує $10^{-12} \%$, що вказує на коректність проведеного аналізування. Отримані аналітичні залежності готові до програмування.

Результати досліджень подані у вигляді графічних залежностей кінематичних параметрів різця, зрівноважувального моменту, зведених до урухомчої ланки моменту сил опору та моменту інерції, реакції між стояком і поковзнем від кута обертання корби. В обертальних кінематичних парах побудовані годографи реакцій.

Наведена динамічна і математична модель руху механізму і визначені іiі параметри. Показано технологію визначення потужності електродвигуна на прикладі механізму довбального верстата, де момент рушійних сил залежить від кутової швидкості, а момент інерції - різко нелінійна функція. Стійку ділянку роботи електродвигуна апроксимовано прямою лінією, а момент сил опору - вектором значень.

Для забезпечення руху різця 3 квазінульовою швидкістю у середині кінематичного циклу запропоновано: застосувати механізм, в якому довжину корби потрібно змінювати за заданою програмою залежно від кута повороту корби; синтезувати новий або використати відомий закон зміни довжини корби, за якого рух різця відбуватиметься без м'яких ударів із ділянкою квазінульової швидкості різця у середині кінематичного циклу.

Ключові слова: важільні механізми, механізм довбального верстата, кінематичні і кінетостатичні характеристики важільних механізмів.

Pasika V., Koruniak P., Zokhniuk V., Roman D. Dynamic analysis of the slotting machine mechanism

The article studies the kinematic characteristics of the links and individual points of the mechanism by using the method of closed geometric contours and the method of designing plans. The forces of interaction between the links of the mechanism are determined by the method of kinetostatics, and the balancing moment - by considering the dynamic equilibrium of the crank. Moreover, the balancing moment is determined by the method of power balance. The error does not exceed $10^{-12} \%$, which indicates the correctness of the analysis. The obtained analytical dependencies are ready for programming.

The research results are presented in the form of graphical dependencies of the cutter kinematic parameters, the balancing torque, the torque of resistance forces, reduced to the moving link and the moment of inertia, the reaction force between the riser and the slide on the angle of rotation. Hodographs of reactions forces were created for rotating kinematic pairs.

The dynamic and mathematical models of the mechanism motion are shown and their parameters are determined. The technology of determining the power of the electric motor is shown on the example of the slotting machine mechanism, where the torque of driving forces depends on the angular velocity, and the moment of inertia is a sharply nonlinear function. The stable part of the motor operation is approximated to a straight line, and the torque of resistance forces - to the vector of values.

To ensure the movement of the cutter with a quasi-zero speed in the middle of the kinematic cycle, it is proposed: to apply a mechanism in which the length of the crank must be changed according to a given program depending on the rotation of the crank; to synthesize a new law of change in the length of the crank or use a known one, under which the cutter moves without soft shocks and with a quasi-zero speed section in the middle of the kinematic cycle.

Key words: lever mechanisms, slotting machine mechanism, kinematic and kinetostatic characteristics of lever mechanisms. 
Постановка проблеми. Довбальні верстати застосовують як у серійному виробництві, так і в ремонтних майстернях для одержання канавок, пласких і фасонних поверхонь невеликої висоти, але значних поперечних розмірів, наскрізних $\mathrm{i}$ глухих отворів та порожнин. Основним механізмом довбальних верстатів $€$ кулісний 3 приєднаною до нього двоповідковою групою, поковзень якої рухається у вертикальній площині. Продуктивність верстата обмежена швидкістю стругання (70-80 м/хв), через вертально-поступні рухи поковзня, з яким жорстко з'єднаний різець. Рух різця на робочому ходу не є рівномірним, що погіршує якість поверхні стругання, довговічність роботи різця. Наявність на краях кінематичного циклу стрибків пришвидшення різця спричинює м'які удари, що погіршує динамічний стан механізму в цілому i, як наслідок, додатково погіршує якість поверхні стругання.

Аналіз останніх досліджень і публікацій. Праці, в яких було б проведено аналітичні й динамічні дослідження механізму довбального верстата, авторам невідомі. Аналітичні методи дослідження важільних механізмів наведені, наприклад, в [1; 3-7; 9]. У працях [3-5] кінематичне аналізування проведене методом векторних контурів в аналогах, а кінетостатичне - методом проєктування планів. Оскільки більшість кінематичних і кінетостатичних параметрів $\epsilon$ векторними величинами, то доцільно було б визначити й кути нахилу векторів. Деякі структурні групи подані не в найбільш загальному вигляді. Для структурної групи II виду, коли позиція поковзня буде в іншому квадранті, кути нахилу гонка без додаткових обчислень визначити неможливо. У роботах $[1 ; 3]$ наведено базові алгоритми кінематичного i кінетостатичного аналізів, які зашиті в комп'ютерні програми на алгоритмічній мові Фортран, яку на сьогодні практично не застосовують. Автори використовують аналітичні залежності, отримані в роботах $[6 ; 7 ; 9]$, в яких аналітичні вирази для обчислення кінематичних і кінетостатичних характеристик важільних механізмів другого класу подані в найбільш загальному вигляді, придатному для програмування.

Постановка завдання. Перед авторами стояло завдання:

- визначити кінематичні характеристики ланок механізму і сил взаємодії між ними;

- побудувати математичну модель руху механізму і визначити ії параметри;
- намітити напрями поліпшення динамічного стану механізму і забезпечити рух різця 3 квазісталою швидкістю у середині кінематичного циклу.

Виклад основного матеріалу. Структурна схема механізму показана на рис. 1 і містить: корбу $O A-1$, кулісний камінь - 2, кулісу $A B C-3$, гонок $C D-4$ і поковзень $D D_{1}-5$, до якого перпендикулярно прикріплений різець і на який діє сила стругання $F_{\mathrm{p}}$. Аналізування проводимо на основі структурної кваліфікації механізмів за Ассуром, згідно 3 якою структурна формула побудови механізму така:

$$
I(0-1) \rightarrow I I(2-3) \rightarrow I I(4-5) .
$$

Кінематичне аналізування проводимо 3 початку структурної формули за залежностями, отриманими у [7-9]. 3 центром обертання корби пов'язуємо праву систему координат $x O y$. Уважаємо відомими: частоту обертання корби, геометричні та інерційні характеристики ланок, залежність сили стругання $F_{\mathrm{p}}$ від переміщення різця (рис. 2).

Визначення кінематичних характеристик механізму проводимо погрупно 3 початку структурної формули (1).

\section{Корба ОА}

$$
v_{A}=\omega l_{O A} \quad \gamma_{a}=\varphi_{1}-\pi, a_{A}=\omega^{2} l_{O A}, \psi_{a}=\varphi_{1}+\pi,
$$

де $v_{A} \mathrm{i} \gamma_{a}$-модуль $\mathrm{i}$ кут нахилу вектора швидкості $\vec{v}_{A}$ до осі абсцис, $a_{A}$ i $\psi_{a}$-модуль і кут нахилу вектора пришвидшення $\vec{a}_{A}$ до осі абсцис.

Структурна група $A B C$

$$
\begin{gathered}
x_{B}=l_{O B} ; \quad y_{B}=0 ; \quad l_{A B}=\sqrt{\left(x_{A}-x_{B}\right)^{2}+\left(y_{A}-y_{B}\right)^{2}}, \\
\varphi_{3}=\operatorname{arctg}\left(\frac{y_{A}-y_{B}}{x_{A}-x_{B}}\right), \\
\omega_{3}=v_{A} \sin \left(\gamma_{A}-\varphi_{3}\right) / l_{A B}, \quad v_{A_{3} A}=v_{A} \cos \left(\gamma_{A}-\gamma_{3}\right), \\
\varepsilon_{3}=\left[a_{A} \sin \left(\psi_{A}-\varphi_{3}\right)+2 \omega_{3} v_{A_{3} A}\right] / l_{A B}, \\
a_{A_{3} A}=-a_{A} \cos \left(\psi_{A}-\varphi_{3}\right)-\omega_{3}^{2} l_{A B} .
\end{gathered}
$$

Кінематичні характеристики кінематичної пари (КП) $C$ :

$$
\begin{gathered}
x_{C}=x_{B}+l_{B C} \cos \left(\varphi_{3}+\pi\right), \quad y_{C}=y_{B}+l_{B C} \sin \left(\varphi_{3}+\pi\right), \\
l_{C}=\sqrt{x_{C}^{2}+y_{C}^{2}}, \quad \varphi_{C}=\operatorname{arctg}\left(y_{C} / x_{C}\right), \\
v_{C}=l_{B C}\left|\omega_{3}\right|, \quad \gamma_{C}=\varphi_{3}+\pi+0,5 \pi \cdot \operatorname{sign}\left(\varphi_{3}\right), \\
a_{C}=l_{B C} \sqrt{\omega_{3}^{4}+\varepsilon_{3}^{2}}, \quad \psi_{C}=\varphi_{3}-\operatorname{arctg}\left(\varepsilon_{3} / \omega_{3}^{2}\right) .
\end{gathered}
$$




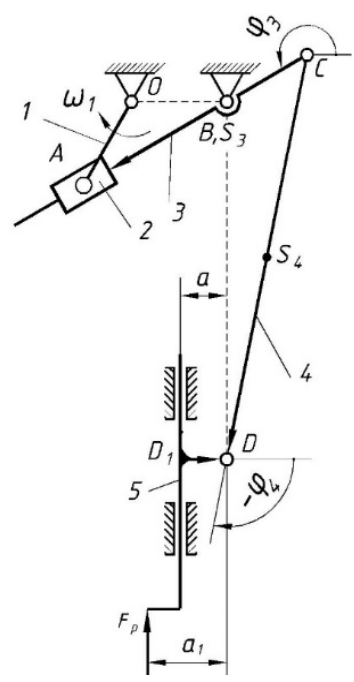

Рис. 1. Структурна схема механізму

Fig. 1. Block diagram of the mechanism

Структурна група $C D$

$\xi \square$ кут нахилу напрямної 5 до осі абсцис, $x_{E}=1, y_{E}=0, \quad z e=\operatorname{sign}\left\{\operatorname{sign}\left[y_{E} \cos (\xi)\right]-\operatorname{sign}\left[x_{E} \sin (\xi)\right]\right\}$,

$$
\begin{gathered}
\varphi_{4}=\arcsin \left[e \cdot z e+a-l_{C} \sin \left(\varphi_{C}-\xi\right)\right] / l_{4}+\xi, \quad e=l_{O B}-a, \\
y_{D}=l_{C} \sin \left(\varphi_{C}\right)+l_{4} \sin \left(\varphi_{4}\right)-a, \quad s_{D}=y_{D}(1)-y_{D}, \\
\omega_{4}=\frac{v_{C} \sin \left(\xi-\gamma_{C}\right)}{l_{4} \cos \left(\varphi_{4}-\xi\right)}, \quad v_{D}=\frac{v_{C} \cos \left(\varphi_{4}-\gamma_{C}\right)}{\cos \left(\varphi_{4}-\xi\right)}, \\
a_{D}=\frac{a_{C} \cos \left(\psi_{C}-\varphi_{4}\right)-\omega_{4}^{2} l_{4}}{\cos \left(\varphi_{4}-\xi\right)}, \\
\varepsilon_{4}=\frac{-a_{C} \sin \left(\psi_{C}-\xi\right)+\omega_{4}^{2} l_{4} \sin \left(\varphi_{4}-\xi\right)}{l_{4} \cos \left(\varphi_{4}-\xi\right)}, \\
\gamma_{D}=\xi+\frac{\pi\left[1-\operatorname{sign}\left(v_{D}\right)\right]}{2}, \psi_{D}=\xi+\frac{\pi\left[1-\operatorname{sign}\left(a_{D}\right)\right]}{2} .
\end{gathered}
$$

Кінематичні характеристики вектора пришвидшення центра ваги $S_{4}$ гонка $C D$ :

$$
a_{S_{4}}=y_{a_{54}} / \sin \left(\psi_{S_{4}}\right), \quad \psi_{S_{4}}=\operatorname{arctg}\left(y_{a_{54}} / x_{a_{54}}\right),
$$

де

$$
\begin{aligned}
& y_{a_{S 4}}=a_{C} \sin \left(\psi_{C}\right)-\omega_{4}^{2} l_{C S_{4}} \sin \left(\varphi_{4}\right)+\varepsilon_{4} l_{C S_{4}} \cos \left(\varphi_{4}\right), \\
& x_{a_{S 4}}=a_{C} \cos \left(\psi_{C}\right)-\omega_{4}^{2} l_{C S_{4}} \cos \left(\varphi_{4}\right)-\varepsilon_{4} l_{C S_{4}} \sin \left(\varphi_{4}\right) .
\end{aligned}
$$

Аналізування проведено для таких даних механізму:

$$
n_{1}=120 \mathrm{o \sigma} / \mathrm{xB}, l_{O A}=0,12 \mathrm{M} ; l_{O B}=0,04 \mathrm{M} ; a=0,03 \mathrm{M} \text {; }
$$$$
a_{1}=l_{B C}=0,08 \mathrm{M} ; l_{C D}=0,35 \mathrm{~m} ; l_{C S_{4}}=l_{C D} / 2 \text {; }
$$$$
l_{D S_{4}}=l_{C_{4}}, \varphi_{50}=\pi / 2 ; \varphi_{5}=0 ; m_{2}=0 \kappa \Gamma ; m_{1}=5 \kappa \% ;
$$

Fig. 2. Planing force

$$
m_{3}=22 \mathrm{\kappa} \Gamma ; m_{4}=6 \kappa \Gamma ; m_{5}=34 \kappa \Gamma ;
$$

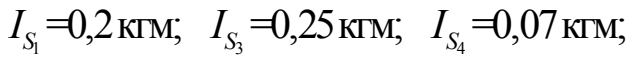

$$
F_{\mathrm{p}}=1500 \mathrm{H} ; g=9,81 \mathrm{~m} / \mathrm{c}^{2} \text {. }
$$

Кінематичні характеристики різця показані на рис. 3.

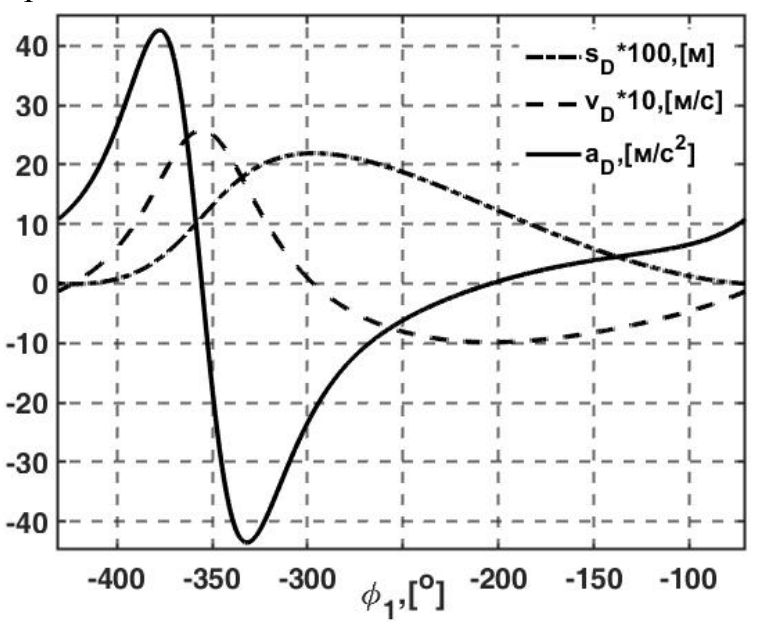

Рис. 3. Кінематичні характеристики поковзня (різця)

Fig. 3. Kinematic characteristics of the slider (cutter)

Результати аналізування підтверджують той факт, що важільні механізми не забезпечують руху урухомної ланки 3 ділянкою квазісталої швидкості. Початок і кінець процесу стругання відбува$€$ ться зі стрибка пришвидшення $a_{D}$, що викликає ефект м'якого удару і призводить до погіршення динамічного стану верстата і його продуктивності. Щоб уникнути небажаних явищ, необхідно: 
- синтезувати або використати відомі закони періодичного руху [8], в яких відсутні м'які удари, а у середині кінематичного циклу спостерігаємо ділянку квазісталої швидкості;

- для забезпечення руху різця за синтезованим або вибраним законом корбу сталої довжини замінити корбою змінної довжини [10]. У такому разі задачу зводять до синтезу такої змінної довжини корби, за якої різець рухатиметься за синтезованим або вибраним законом.

Кінетостатичне аналізування проводимо погрупно 3 кінця структурної формули (1) за залежностями, отриманими у [6; 7].

Обчислюємо інерційне навантаження ланок механізму.

Сили ваги ланок визначаємо за очевидною залежністю $G_{i}=m_{i} \mathrm{~g}$, де $m_{i}-$ маса $i$ ланки.

Вектори сил інерції ланок $C D$ :

$$
F_{S_{4}}=m_{4} a_{S_{4}} ; \alpha_{S_{4}}=\psi_{S_{4}}+\pi ; \text { поковзня } D:
$$

$$
\begin{gathered}
x_{43}=\left[\frac{\frac{-\sin (\xi)}{l_{4}} \sum M_{D 4 v}-\cos \left(\varphi_{4}\right) \cdot \cos (\xi)\left(\sum \mathrm{F}_{4 x v}+\sum F_{5 x v}\right)-\cos \left(\varphi_{4}\right) \sin (\xi)\left(\sum F_{4 y v}+\sum F_{5 y v}\right)}{\cos \left(\varphi_{4}-\xi\right)}\right] ; \\
y_{43}=\left[\frac{\frac{\cos (\xi)}{l_{4}} \sum M_{D 4 v}-\sin \left(\varphi_{4}\right) \cdot \cos (\xi)\left(\sum \mathrm{F}_{4 x v}+\sum F_{5 x v}\right)-\sin \left(\varphi_{4}\right) \sin (\xi)\left(\sum F_{4 y v}+\sum F_{5 y v}\right)}{\cos \left(\varphi_{4}-\xi\right)}\right],
\end{gathered}
$$

де $\Sigma F_{4 x v}=F_{\mathrm{S}_{4}} \cos \left(\alpha_{S_{4}}\right), \Sigma F_{4 y v}=F_{\mathrm{S}_{4}} \sin \left(\alpha_{S_{4}}\right)-G_{4}$,

$\Sigma F_{5 \mathrm{xv}}=0, \Sigma F_{5 \mathrm{yv}}=-G_{5}+F_{\mathrm{S}_{5}} \sin \left(\alpha_{S_{5}}\right)+F_{\mathrm{p}} \sin \left(\alpha_{\mathrm{p}}\right)$,

$\Sigma M_{D 4 \mathrm{v}}=G_{4} l_{D S_{4}} \cos \left(\varphi_{4}\right)-F_{S_{4}} l_{D S_{4}} \sin \left(\alpha_{S_{4}}-\varphi_{4}\right)+M_{S_{4}}$,

$F_{\mathrm{p}}, \alpha_{\mathrm{p}}$ - модуль і кут нахилу сили стругання.

Визначаємо реакцію у КП $C$ - дію на гонок 4 куліси 3: сил інерції $i$ ланки до осі абсцис.

Моменти сил інерції ланок:

Структурна група $C D$

Реакція напрямної на поковзень 5:

$$
\begin{gathered}
R_{50}=\left[-\Sigma M_{D 4 v} / l_{4}+\sin \left(\varphi_{4}\right)\left(\Sigma F_{4 v v}+\Sigma F_{5 x v}\right)-\right. \\
\left.-\cos \left(\varphi_{4}\right)\left(\Sigma F_{4 y v}+\Sigma F_{5 y v}\right)\right] / \cos \left(\varphi_{4}-\xi\right) \vec{R}_{43}, \\
\alpha_{50}=\xi+0,5 \pi \cdot \operatorname{sign}\left(R_{50}\right),
\end{gathered}
$$

$F_{5}=m_{5} a_{D}, \alpha_{S_{5}}=\psi_{D}+\pi$, де $\alpha_{S i}-$ кут нахилу вектора 
Ілюстрації деяких кінетостатичних величин наведені на рис. 4, 5 .

Для перевірки правильності проведених досліджень визначено зрівноважувальний момент методом балансу потужності:

$$
M_{\text {зр } \sigma}=\left(P_{G}+P_{M}+P_{F S}+P_{F p}\right) / \omega_{1},
$$

де

$$
P_{G}=G_{4} v_{S_{4}} \cos \left(270-\gamma_{S_{4}}\right)+G_{5}\left|v_{D}\right| \cos \left(270-\gamma_{D}\right)
$$

потужність сил ваги, $P_{M}=M_{S_{3}} \omega_{3}+M_{S_{4}} \omega_{4} \quad-$ потужність моментів сил інерції, $P_{F S}=\left|F_{S_{4}} v_{S_{4}}\right| \cos \left(\alpha_{S_{4}}-\gamma_{S_{4}}\right)+\left|F_{S_{5}} v_{D}\right| \cos \left(\alpha_{S_{5}}-\gamma_{D}\right) \quad$ - потужність сил інерції, $P_{F \mathrm{p}}=\left|F_{\mathrm{p}} v_{D}\right| \cos \left(\alpha_{\mathrm{p}}-\gamma_{D}\right)$ - потужність сили стругання.

Похибка між зрівноважувальними моментами не перебільшує $10^{-12} \%$, що підтверджує правильність проведених досліджень.

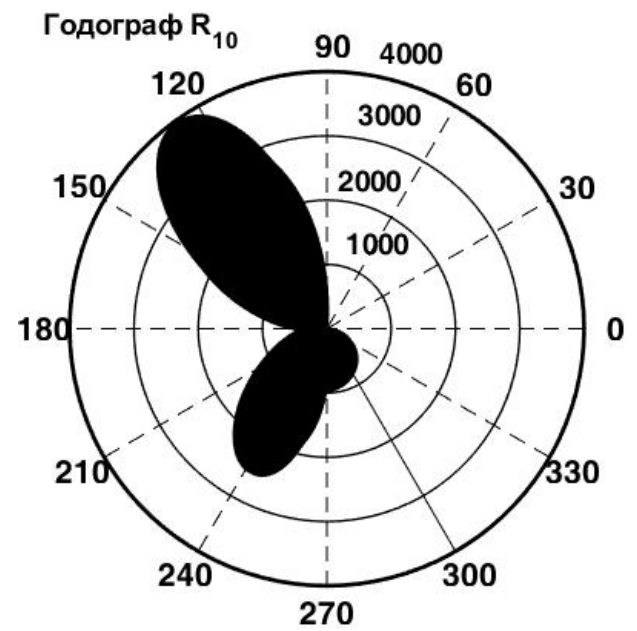

a

Рис. 4. Годографи реакцій у кінематичних парах О (а) і В (б)

Fig. 4. Hodographs of reactions in kinematic pairs $\mathrm{O}(\mathrm{a})$ and $\mathrm{B}$ (б)

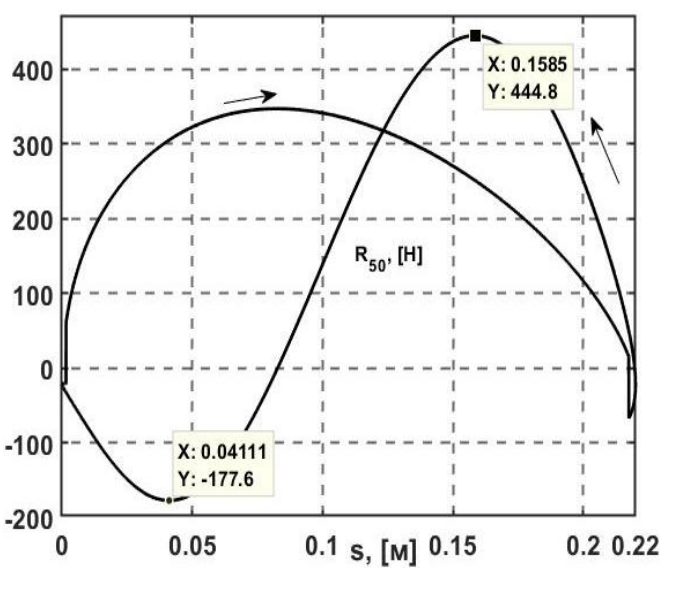

a

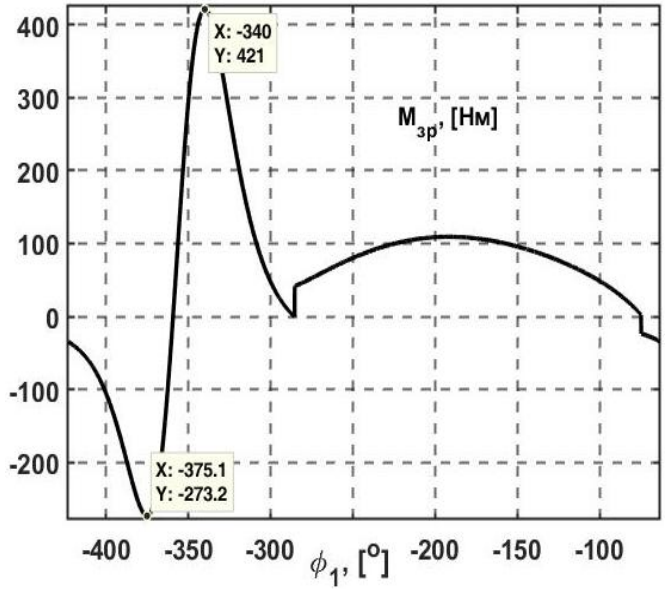

б

Рис. 5. Реакція стояка на поковзень (а) та зрівноважувальний момент (б)

Fig. 5. Response of the riser to the slide (a) and balancing torque (б) 


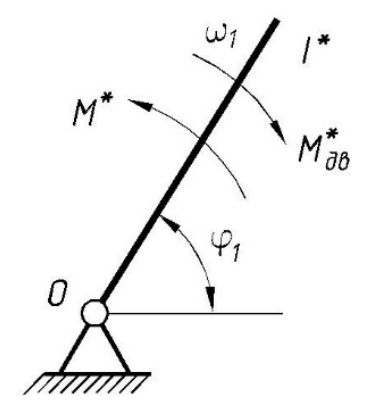

Рис. 6. Динамічна модель механізму

Fig. 6. Dynamic model of the mechanism

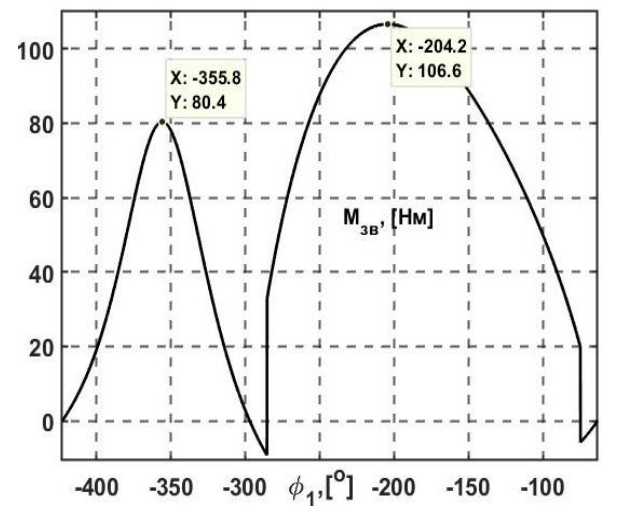

a

Зведений до корби момент інерції механізму (рис. 7, б) визначаємо з умови рівності кінетичної енергії ланки зведення і механізму:

$$
I_{\mathrm{M}}^{*}=I_{S_{1}}+I_{S_{3}}\left(\frac{\omega_{3}}{\omega_{1}}\right)^{2}+m_{4}\left(\frac{v_{S_{4}}}{\omega_{1}}\right)^{2}+I_{S_{4}}\left(\frac{\omega_{4}}{\omega_{1}}\right)^{2}+m_{5}\left(\frac{v_{D}}{\omega_{1}}\right)^{2}
$$

Зведений момент інерції електродвигуна

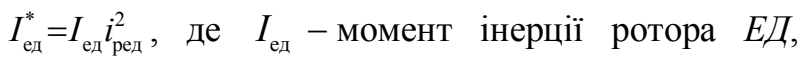
$i$ - передавальне число редуктора, які визначають за паспортними даними.

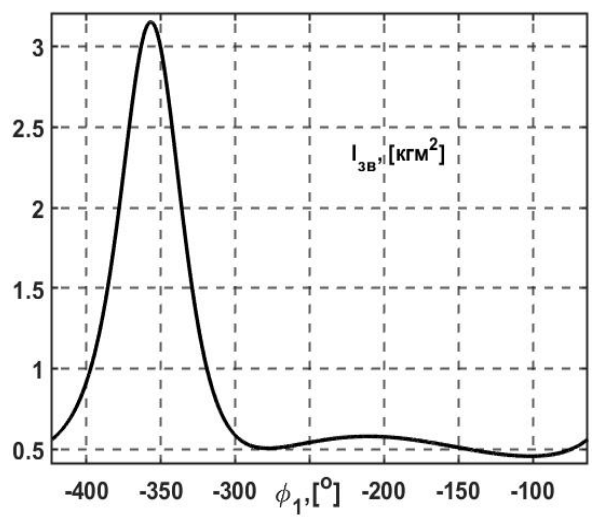

б

Рис. 7. Зведений до корби момент сил опору (а) та момент інерції механізму (б)

Fig. 7. Reduced torque of resistance forces (a) and inertia moment of the mechanism (б)

Щоб обчислити зведений момент інерції редуктора, необхідно знати кількість проміжних валів. Наведемо приклад визначення моментів інерції для редукторів з одним проміжним валом, які $\epsilon$ найпоширенішими. У таких редукторах $\epsilon$ вхідний і вихідний вали, які з'єднані між собою проміжним валом через циліндричні зубчасті колеса. Зведений до корби момент інерції такого редуктора визначаємо 3 рівності кінетичних енергій редуктора і ланки зведення:

$$
I_{\text {ред }}^{*}=I_{1 \mathrm{p}}\left(\frac{\omega_{\text {ед }}}{\omega_{1}}\right)^{2}+I_{2 \mathrm{p}}\left(\frac{\omega_{2 \mathrm{p}}}{\omega_{1}}\right)^{2}+I_{3 \mathrm{p}}
$$

де $I_{1 \mathrm{p}}, I_{2 \mathrm{p}}, I_{3 \mathrm{p}}$ - моменти інерції вхідного, проміжного і вихідного валів редуктора, $\omega_{2 p}$ - кутова швидкість проміжного вала.

За паспортними даними редукторів можна наближено оцінити момент інерції редуктора. Коли редуктор проєктують, то моменти інерції валів визначають точно CAD програмами, в яких проведено проєктування.

Вибір потужності електродвигуна

За урухомлювач приймаємо асинхронний електродвигун, механічна характеристика якого показана на рис. 8. Стійку частину $H C$ механічної характеристики роботи електродвигуна наближено апроксимуємо прямою лінією:

$$
M_{\text {ед }}=A \omega+B \text {, }
$$

де коефіцієнти $A=\frac{M_{\text {н }}}{\omega_{\text {н }}-\omega_{\mathrm{c}}}$ і $B=-A \omega_{\text {с }}$ визначаємо за очевидними умовами: для $\omega=\omega_{\mathrm{H}} \rightarrow M_{\text {ед }}=M_{\mathrm{н}}$, $\omega=\omega_{\mathrm{c}} \rightarrow M_{\text {ед }}=0, \omega_{\text {н }}$ і $\omega_{\mathrm{c}}-$ номінальна $\mathrm{i}$ синхронна кутові швидкості ЕД.

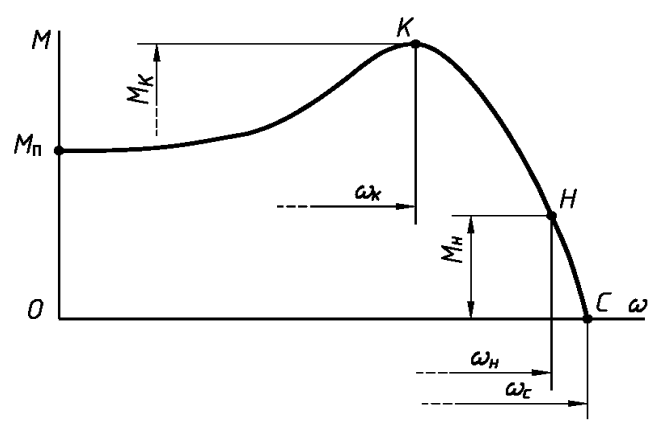

Рис. 8. Механічна характеристика асинхронного електродвигуна

Fig. 8. Mechanical characteristics of the induction motor 
Момент електродвигуна зведений до корби:

$$
M_{\text {ед }}^{*}=i \cdot(A \omega+B) .
$$

Конкретний ЕД вибираємо за максимальною величиною моменту сил опору $M_{\text {о } \max } \approx 106,6$ Нм (див. рис. 7, a), який створює на валу корби потужність $P_{1}=M_{\text {omax }} \omega_{1}=1,34$ кВт, де $\omega_{1}=12,57 \mathrm{c}^{-1}$ - частота обертання корби. Оскільки

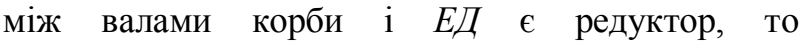
розрахункова потужність на валу ЕД 3 урахуванням коефіцієнта корисної дії редуктора буде $P_{\text {едр }}=P_{1} / \eta \approx 1,45 \kappa \mathrm{КТ}$, де $\eta=0,92-$ коефіцієнт двосхідчастого циліндричного редуктора 3 двома парами прямозубих i косозубих коліс. Зі стандартного ряду [11] вибираємо ЕД 4АМ80А2 3 такими характеристиками:

$$
\begin{gathered}
P_{\mathrm{H}}=1,5 \kappa \mathrm{\kappa Т}, n_{\mathrm{c}}=3000 \text { об } / \text { хв }, \omega_{\mathrm{c}}=298,3 \mathrm{c}^{-1}, \\
n_{\mathrm{H}}=2850 \text { об } / \mathrm{xB}, \omega_{\mathrm{H}}=314 \mathrm{c}^{-1}, \\
M_{\text {max }} / M_{\mathrm{H}}=2,2, M_{\text {пус }} / M_{\mathrm{H}}=2 .
\end{gathered}
$$

Обчислюємо номінальний момент ЕД $M_{\text {н }}=P_{\text {н }} / \omega_{\mathrm{H}}=5,03 \mathrm{Hм}$, коефіцієнти $A=-3,12 \mathrm{Hмc} \mathrm{і}$ $B=980,08$ Нм. Тоді момент електродвигуна буде таким:

$$
M_{\text {ед }}=-3,12 \omega+980,08 \text { Нм . }
$$

Момент сил опору, зведений до корби, заданий у вигляді вектора значень і показаний на рис. 7, а.

Таким чином, усі параметри, які входять у рівняння (2), визначені за (3) - (5) і (2) (див. пояснення). Рівняння диференціальне, нелінійне першого порядку, розв'язувати яке потрібно числовим методом.

Висновки. Проведено перший етап удосконалення головного механізму довбальних верстатів і отримано аналітичні залежності для обчислення кінематичних та динамічних характеристик. Наведено числову перевірку правильності проведених обчислень кінематичних i кінетостатичних характеристик. Похибка становить $10^{-12} \%$ для величини зрівноважувального моменту, обчисленого за методом планів і балансу потужності. Визначено параметри динамічної моделі руху механізму 3 урухомлювачем від асинхронного електродвигуна. Намічено напрями вдосконалення механізму 3 метою підвищення продуктивності та чистоти стругання.

\section{Бібліографічний список}

1. Белоконев И. М. Теория механизмов и машин. Методы автоматизированного проектирования. Киев: Вища шк., 1990. 208 с.

2. Заблонский К. И., Белоконев И. М., Щёкин Б. М. Теория механизмов и машин. Киев: Вища шк., 1989. 376 с.

3. Кіницький Я. Т. Теорія механізмів і машин. Київ: Наук. думка, 2002. 660 с.

4. Кіницький Я. Т., Х Харжевський В. О., Марченко М. В. Теорія механізмів і машин в системі Mathcad: навч. посіб. Хмельницький: ХНУ, 2014. 295 с.

5. Курсове проектування 3 теорії механізмів i машин: навч. посіб. / Є. І. Крижанівський та ін. ІваноФранківськ, 1996. 357 с.

6. Пасіка В.Р. Аналітичний метод планів у кінетостатичному аналізі важільних механізмів II класу. Поліграфія і видавнича справа. 2002. № 38. С. 43-62.

7. Пасіка В. Р., Гелетій В. М. Аналітичний метод у дослідженні важільних механізмів II класу. Львів; Дрогобич: ПОСВIT, 2019. 142 с.

8. Пасіка В. Р., Гелетій В. М., Сологуб Б. В. Кінематичне синтезування законів періодичного руху: монографія. Львів: Левада, 2021. 123 с.

9. Пасіка В. Р. Кінематика важільних механізмів 3 групами Ассура III-V видів. Поліграфія $i$ видавнича справа. 2001. № 1. С. 36-40.

10. Пасіка В. Р., Полюдов О. М. Геометричний синтез кривошипно-повзунних механізмів за заданим переміщенням повзуна. Науковий вісник: зб. наук.-техн. праць. Львів: УкрДЛТУ, 2002. Вип. 12.8. С. 174-179.

11. Ромасевич Ю. О., Рибалко В. М., Матухно Н. В. Вибір електродвигунів для машин і механізмів, які забезпечують виробничі процеси у сільському $\mathrm{i}$ лісовому господарстві. Київ, 2015. 75 с. URL: https://nubip.edu.ua/sites/default/files/u132/\%D0\%9C $\%$ D0 $\% \mathrm{~B} 5 \% \mathrm{D} 1 \% 82 \% \mathrm{D} 0 \% \mathrm{BE} \% \mathrm{D} 0 \% \mathrm{~B} 4 \% \mathrm{D} 0 \% \mathrm{~B} 8 \% \mathrm{D} 1 \% 87 \% \mathrm{D} 0$ $\%$ BA\%D0\%B0_\%D0\%92\%D0\%B8\%D0\%B1\%D1\%96\% D1\%80\%20\%D0\%B5\%D0\%BB $\%$ D0\%B5\%D0\%BA\%D1 $\% 82 \% \mathrm{D} 1 \% 80 \% \mathrm{D} 0 \% \mathrm{BE} \% \mathrm{D} 0 \% \mathrm{~B} 4 \% \mathrm{D} 0 \% \mathrm{~B} 2 \% \mathrm{D} 0 \% \mathrm{~B} 8 \% \mathrm{D} 0$ $\% \mathrm{~B} 3 \% \mathrm{D} 1 \% 83 \% \mathrm{D} 0 \% \mathrm{BD} \% \mathrm{D} 1 \% 96 \% \mathrm{D} 0 \% \mathrm{~B} 2 \% 20 \% \mathrm{D} 0 \% \mathrm{~B} 4$ $\% \mathrm{D} 0 \% \mathrm{BB} \% \mathrm{D} 1 \% 8 \mathrm{~F} \% 20 \% \mathrm{D} 0 \% \mathrm{BC} \% \mathrm{D} 0 \% \mathrm{~B} 0 \% \mathrm{D} 1 \% 88 \% \mathrm{D}$ $0 \% \mathrm{~B} 8 \% \mathrm{D} 0 \% \mathrm{BD} \% 20 \% \mathrm{D} 1 \% 96 \% 20 \% \mathrm{D} 0 \% \mathrm{BC} \% \mathrm{D} 0 \% \mathrm{~B} 5 \%$ D1\%85\%D0\%B0\%D0\%BD $\%$ D1 $\% 96 \% \mathrm{D} 0 \% \mathrm{~B} 7 \% \mathrm{D} 0 \% \mathrm{BC}$ $\% \mathrm{D} 1 \% 96 \% \mathrm{D} 0 \% \mathrm{~B} 2 \% 2 \mathrm{C} \% 20 \% \mathrm{D} 1 \% 8 \mathrm{~F} \% \mathrm{D} 0 \% \mathrm{BA} \% \mathrm{D} 1 \% 96$ $\% 20 \% \mathrm{D} 0 \% \mathrm{~B} 7 \% \mathrm{D} 0 \% \mathrm{~B} 0 \% \mathrm{D} 0 \% \mathrm{~B} 1 \% \mathrm{D} 0 \% \mathrm{~B} 5 \% \mathrm{D} 0 \% \mathrm{~B} 7 \% \mathrm{D}$ 0\%BF\%D0\%B5\%D1\%87\%D1\%83\%D1\%8E\%D1\%82\%D $1 \% 8 \mathrm{C} \% 20 \% \mathrm{D} 0 \% \mathrm{~B} 2 \% \mathrm{D} 0 \% \mathrm{~B} 8 \% \mathrm{D} 1 \% 80 \% \mathrm{D} 0 \% \mathrm{BE} \% \mathrm{D} 0 \% \mathrm{~B}$ $1 \% \mathrm{D} 0 \% \mathrm{BD} \% \mathrm{D} 0 \% \mathrm{~B} 8 \% \mathrm{D} 1 \% 87 \% \mathrm{D} 1 \% 96 \% 20 \% \mathrm{D} 0 \% \mathrm{BF} \% \mathrm{D}$ $1 \% 80 \% \mathrm{D} 0 \% \mathrm{BE} \% \mathrm{D} 1 \% 86 \% \mathrm{D} 0 \% \mathrm{~B} 5 \% \mathrm{D} 1 \% 81 \% \mathrm{D} 0 \% \mathrm{~B} 8 \% 2$ $0 \% \mathrm{D} 1 \% 83 \% 20 \% \mathrm{D} 1 \% 81 \% \mathrm{D} 1 \% 96 \% \mathrm{D} 0 \% \mathrm{BB} \% \mathrm{D} 1 \% 8 \mathrm{C} \% \mathrm{D}$ $1 \% 81 \% \mathrm{D} 1 \% 8 \mathrm{C} \% \mathrm{D} 0 \% \mathrm{BA} \% \mathrm{D} 0 \% \mathrm{BE} \% \mathrm{D} 0 \% \mathrm{BC} \% \mathrm{D} 1 \% 83 \%$ $20 \% \mathrm{D} 1 \% 96 \% 20 \% \mathrm{D} 0 \% \mathrm{BB} \% \mathrm{D} 1 \% 96 \% \mathrm{D} 1 \% 81 \% \mathrm{D} 0 \% \mathrm{BE} \%$ D0\%B2\%D0\%BE\%D0\%BC\%D1\%83\%20\%D0\%B3\%D0 $\% \mathrm{BE} \% \mathrm{D} 1 \% 81 \% \mathrm{D} 0 \% \mathrm{BF} \% \mathrm{D} 0 \% \mathrm{BE} \% \mathrm{D} 0 \% \mathrm{~B} 4 \% \mathrm{D} 0 \% \mathrm{~B} 0 \% \mathrm{D}$ $1 \% 80 \% \mathrm{D} 1 \% 81 \% \mathrm{D} 1 \% 82 \% \mathrm{D} 0 \% \mathrm{~B} 2 \% \mathrm{D} 1 \% 96 . \mathrm{pdf} \quad$ (дата звернення: 24.08.2021).

12. Юдин В. А., Петрокас Л. В. Теория механизмов и машин. Москва: Высш. шк., 1977. 528 с. 